\title{
Dissolution of minerals and metal oxides in ice and its implication for polar region
}

\author{
Kitae Kim $^{1}$
}

1 Korea Polar Research Institute (KOPRI), Incheon 21990, Korea (ktkim@kopri.re.kr)

Chemical weathering of minerals or rocks is important source of nutrients and realted to the removal mechanism of atmospheric carbon dioxide in geological timescales. It is known that the rate of chemical weathering is higher in high temperature and precipitation region. However, it is found that chemical denudation rates in polar region are comparable to or higher than in temperate watersheds. It is reported that several chemical reactions can be accelerated by freezing. The dissolution of metal oxide(iron oxide and manganese oxide) particles can be accelerated in ice. Nevertheless, there is little experimental study about chemical dissolution of natural minerals and rocks in ice phase whereas many dissolution experiments were performed with various $\mathrm{pH}$ adjustment, temperatures, and organic acids in aqueous phase. Moreover, it is regarded that chemical weathering does not occur in ice in winter season in most of researches for polar region. In this presentation, we will show the experimental results about the dissolution of natural minerals and rocks in water $\left(25^{\circ} \mathrm{C}\right)$ and ice $\left(-20^{\circ} \mathrm{C}\right)$. We found that the dissolution of some minerals and rocks in ice is comparable to aqueous phase. Notably, silica concentrations in dissolution experiments decreased with reaction time in ice. The detailed experimental conditions and mechanism will be discussed in the presentation. 